\title{
Thiazolidinediones partially reverse the metabolic disturbances observed in Bscl2/seipin-deficient mice
}

\author{
X. Prieur • L. Dollet • M. Takahashi • M. Nemani • B. Pillot • \\ C. Le May • C. Mounier • H. Takigawa-Imamura • \\ D. Zelenika • F. Matsuda • B. Fève - J. Capeau $\cdot$ M. Lathrop • \\ P. Costet • B. Cariou • J. Magré
}

Received: 20 February 2013 / Accepted: 11 April 2013 /Published online: 17 May 2013

(C) Springer-Verlag Berlin Heidelberg 2013

\begin{abstract}
Aims/hypothesis Mutations in BSCL2/seipin cause Berardinelli-Seip congenital lipodystrophy (BSCL), a rare recessive disorder characterised by near absence of adipose tissue and severe insulin resistance. We aimed to determine how seipin deficiency alters glucose and lipid homeostasis and whether thiazolidinediones can rescue the phenotype. Methods $\mathrm{Bscl}^{-/-}$mice were generated and phenotyped. Mouse embryonic fibroblasts (MEFs) were used as a model of adipocyte differentiation.

Results As observed in humans, $B s c l 2^{-/-}$mice displayed an early depletion of adipose tissue, with insulin resistance and severe hepatic steatosis. However, $\mathrm{Bscl2}^{-/-}$mice exhibited an unexpected hypotriglyceridaemia due to increased clearance of triacylglycerol-rich lipoproteins (TRL) and uptake of fatty acids by the liver, with reduced basal energy expenditure. In vitro experiments with MEFs demonstrated that
\end{abstract}

X. Prieur, L. Dollet and M. Takahashi contributed equally to this study.

Electronic supplementary material The online version of this article (doi:10.1007/s00125-013-2926-9) contains peer-reviewed but unedited supplementary material, which is available to authorised users.

X. Prieur $(\bowtie) \cdot$ L. Dollet $\cdot$ B. Pillot $\cdot$ C. Le May $\cdot$ P. Costet $\cdot$

B. Cariou $\cdot$ J. Magré $(\bowtie)$

Inserm UMR_S1087, L'Institut du Thorax, IRS-UN, 8 Quai

Moncousu, BP70721, 44007 Nantes Cedex 1, France

e-mail: Xavier.Prieur@univ-nantes.fr

e-mail: Jocelyne.Magre@inserm.fr

X. Prieur

Université de Nantes, Nantes, France

M. Takahashi $\cdot$ D. Zelenika $\cdot$ M. Lathrop

Commissariat à l'Energie Atomique/Institut de Génomique/Centre

National de Génotypage (CEA/IG/CNG), Evry, France

M. Nemani $\cdot$ B. Fève $\cdot$ J. Capeau

UPMC Univ. Paris 06, Inserm UMR_S938, Paris, France seipin deficiency led to impaired late adipocyte differentiation and increased basal lipolysis. Thiazolidinediones were able to rescue the adipogenesis impairment but not the alteration in lipolysis in $\mathrm{Bscl}^{-1-}$ MEFs. In vivo treatment of $B s 2^{-/-}$mice with pioglitazone for 9 weeks increased residual inguinal and mesenteric fat pads as well as plasma leptin and adiponectin concentrations. Pioglitazone treatment increased energy expenditure and improved insulin resistance, hypotriglyceridaemia and liver steatosis in these mice.

Conclusions/interpretation Seipin plays a key role in the differentiation and storage capacity of adipocytes, and affects glucose and lipid homeostasis. The hypotriglyceridaemia observed in $\mathrm{Sscl}^{-/-}$mice is linked to increased uptake of TRL by the liver, offering a new model of liver steatosis. The demonstration that the metabolic complications associated with BSCL can be partially rescued with pioglitazone treatment opens an interesting therapeutic perspective for BSCL patients.

\author{
C. Mounier \\ Université du Quebec à Montreal, BIOMED, Montreal, Canada \\ H. Takigawa-Imamura \\ Anatomy and Cell Biology, Kyushu University Graduate School of \\ Medicine, Fukuoka, Japan \\ F. Matsuda \\ Center for Genomic Medicine, Kyoto University Graduate School \\ of Medicine, Kyoto, Japan \\ B. Fève $\cdot$ J. Capeau \\ Institute of Cardiometabolism and Nutrition, Paris, France \\ P. Costet $\cdot$ B. Cariou \\ L'Institut du Thorax, CHU de Nantes, Nantes, France
}


Keywords Adipocyte differentiation · BSCL $\cdot$ Insulin resistance $\cdot$ Lipodystrophy $\cdot$ Lipolysis $\cdot$ Liver steatosis · Lipoprotein clearance $\cdot$ Seipin $\cdot$ Thiazolidinedione .

Triacylglycerol

$\begin{array}{ll}\text { Abbreviations } \\ \text { ACC } & \text { Acetyl coenzyme A carboxylase } \\ \text { BAT } & \text { Brown adipose tissue } \\ \text { BSCL } & \text { Bernardinelli-Seip congenital lipodystrophy } \\ \text { CD36 } & \text { Scavenger receptor } \\ \text { C/EBP } & \text { CCAAT-enhancer-binding protein } \\ \text { CT } & \text { Computed tomography } \\ \text { FGF-21 } & \text { Fibroblast growth factor 21 } \\ \text { FPLC } & \text { Fast protein liquid chromatography } \\ \text { HSL } & \text { Hormone-sensitive lipase } \\ \text { IPGTT } & \text { Intra-peritoneal glucose tolerance test } \\ \text { ITT } & \text { Insulin tolerance test } \\ \text { LD } & \text { Lipid droplet } \\ \text { LDLr } & \text { LDL receptor } \\ \text { MEF } & \text { Mouse embryonic fibroblast } \\ \text { NEO } & \text { Neomycin cassette } \\ \text { PPAR } & \text { Peroxisome proliferator-activated receptor } \\ \text { SREBP-1c } & \text { Sterol response element binding protein-1c } \\ \text { TAG } & \text { Triacylglycerol } \\ \text { TRL } & \text { Triacylglycerol-rich lipoprotein } \\ \text { TZD } & \text { Thiazolidinedione } \\ \text { WAT } & \text { White adipose tissue }\end{array}$

\section{Introduction}

Adipose tissue plays a key role in whole-body energy homeostasis. The expansion of adipose tissue leads to obesity and related metabolic complications; lipodystrophies (disorders characterised by a partial or complete lack of adipose tissue) are also associated with severe metabolic disturbances. Among the lipodystrophies, Bernardinelli-Seip congenital lipodystrophy (BSCL) displays the most severe phenotype with a combination of insulin resistance, liver steatosis and hypertriglyceridaemia [1]. BSCL is an autosomal recessive disease linked to mutations in either BSCL2, encoding seipin [2], or AGPAT2, encoding 1-acylglycerol-3-phosphate $O$-acyltransferase- $\beta$ [3]. In a few cases, BSCL is due to mutations in the genes encoding either caveolin-1 [4] or cavin-1 [5], both involved in the formation of caveolae [6].

The function of seipin is still unclear. Some studies indicate that seipin is involved in adipogenesis, lipid metabolism and lipid droplet (LD) biogenesis and maintenance [7-12]. Notably, knocking down seipin with short hairpin RNA alters terminal adipocyte differentiation in C3H10T1/2 mesenchymal stem cells [13] or 3 T3-L1 adipocyte cell lines, with a downregulation of transcription factors involved in adipogenesis and of their downstream lipogenic target genes $[13,14]$. The effect of peroxisome proliferator-activated receptor- $\gamma$ (PPAR $\gamma)$ agonists, such as thiazolidinediones (TZDs), on the altered adipogenesis linked to seipin deficiency remains controversial and cell-type dependent. In 3T3L1 cells, pioglitazone was reported to partially rescue the defective adipogenic process due to seipin depletion [14]. In contrast, the same group recently reported that pioglitazone was unable to fully restore the adipogenic programme in seipindeficient $\left(\mathrm{Bscl}^{-/-}\right)$mouse embryonic fibroblast (MEF)derived adipocytes [15].

A major breakthrough in the field of seipin came recently, with the demonstration by two independent groups that $\mathrm{Bscl}^{-/-}$mice develop severe lipodystrophy, validating the hypothesis that seipin has a critical role in adipocyte differentiation in vivo $[15,16]$. In these two models, $\mathrm{Bscl}^{-/-}$ mice presented with a massive, but not complete, loss of white adipose tissue (WAT). These two models displayed several discrepancies concerning their metabolic phenotype. In one study, $\mathrm{Bscl}^{-/-}$mice displayed normal plasma glucose concentrations in the random-fed state [16], while in the second, they were frankly hyperglycaemic [15]. In addition, lipid metabolism in these two models raises several questions. First, in contrast to the human phenotype [1], $\mathrm{Bscl}^{-/-}$mice do not display fasting hypertriglyceridaemia. Second, while these mice exhibit liver steatosis $[15,16]$, the hepatic lipid metabolism has not been explored with in vivo functional studies and therefore remains poorly understood.

The aim of the present study was to unravel how seipin deficiency leads to the metabolic complications associated with BSCL, with a special focus on liver steatosis and dyslipidaemia. To address these issues, we generated a new $\mathrm{Bscl}^{-/-}$mouse model and performed a complete metabolic phenotyping of glucose and lipid homeostasis. Considering therapeutic intervention in BSCL patients, we assessed whether in vivo treatment with TZDs could reverse the phenotype of $B s c l 2^{-/-}$mice.

\section{Methods}

Generation of $\mathrm{Bscl}^{--}$mice and colony maintenance The targeting construct contains a short arm, 1210-bp fragment in the third intron of $B s c l 2$ synthesised by PCR using primers: 5'-GCACAGTGGCACACATCTAT-3' and 5'AGAACTTCACTTGCCTCAGC-3', and a long fragment (XbaI-HpaI, including exons 7-11) excised from a phage clone obtained from an SV-129 mouse genomic library (kindly offered by J. Weissenbach, CEA/IG Centre National de Séquençage, Evry, France). They were inserted into plasmid pG23 (Genoway, Lyons, France) with a neomycin cassette (NEO) in between. The gene map is shown 
in electronic supplementary material (ESM) Fig. 1. Using ES cell-line E14, Bscl2 was modified by homologous recombination, by which exons 4-6 were replaced by NEO. Recombination was screened by PCR and confirmed by Southern blotting. Chimeric mice were obtained by blastocyst injection (Genoway) and germline transmission was confirmed. Mice were backcrossed with $\mathrm{C} 57 \mathrm{BL} / 6 \mathrm{~J}$ for ten generations and heterozygotes were inbred.

Mice were housed in a temperature-controlled room $\left(22^{\circ} \mathrm{C}\right)$ with a $12 \mathrm{~h}$ light-dark cycle. Food and water were freely available. The ethics committees of the local animal facilities approved all animal protocols used in this study. For the in vivo pioglitazone treatment, mice were fed with chow diet (Safe, Augy, France) supplemented with pioglitazone (Actos; Takeda, Puteaux, France) at a concentration of $300 \mathrm{mg} / \mathrm{kg}\left(45 \mathrm{mg} \mathrm{kg}^{-1} \mathrm{day}^{-1}\right)$.
Blood biochemistry Insulin, leptin and fibroblast growth factor 21 (FGF-21) were measured using ELISA kits (Insulin and leptin from Crystal Chem, Downers Grove, IL, USA and FGF-21 from R\&D systems, Lille, France) and adiponectin was quantified with the Milliplex system (Millipore, Molsheim, France). Plasma triacylglycerol (TAG) and cholesterol levels were measured with the triacylglycerol PAP and cholesterol RTU kits, respectively (bioMérieux, Marcy l'Etoile, France). Plasma NEFA concentrations were measured with the NEFA-HR(2) kit (Wako Diagnostics, Richmond, CA, USA). Fast protein liquid chromatography (FPLC) lipoprotein analyses were performed as previously described [17].

Microscanner analyses Adipose tissue distribution was analysed using the Inveon X-ray micro-computed
Fig. $1 \mathrm{Bscl}^{-/-}$mice are lipodystrophic and diabetic. (a) Micro-CT X-ray analysis of 2month-old $\mathrm{Bscl2}^{-/-}$(KO) and wild-type $\mathrm{Bscl}^{+/+}$(WT) male mice. The arrows indicate the localisation of the fat pads that have a dark appearance. (b) Anatomical analysis showing the organomegaly of the liver, intestine and epididymal canal in $\mathrm{Bscl}^{-/-}$mice. (c,d) Plasma adipokine levels of 2-month-old wild-type and $\mathrm{Bscl}^{-1-}$ mice. (e) Daily food intake represents the average values measured over 4 days for individually housed 2-month-old male mice. (f) Glucose levels monitored in the random-fed state every 2 weeks. (g) Fasting insulin levels were measured in 4-month-old male wild-type and $\mathrm{Bscl}^{--}$mice. (h) Glucose tolerance tests and (i) ITTs were performed after $6 \mathrm{~h}$ fasting in 4-month-old male wild-type (triangles, solid line) and $\mathrm{Bscl}^{-/-}$(circles, dashed line) mice ( $n=6$ mice per group). The histograms represent the area under the curve (AUC). The bars represent the SEM; ${ }^{*} p<0.05,{ }^{* *} p<0.01$, $* * * p<0.001$ compared with wild-type mice a
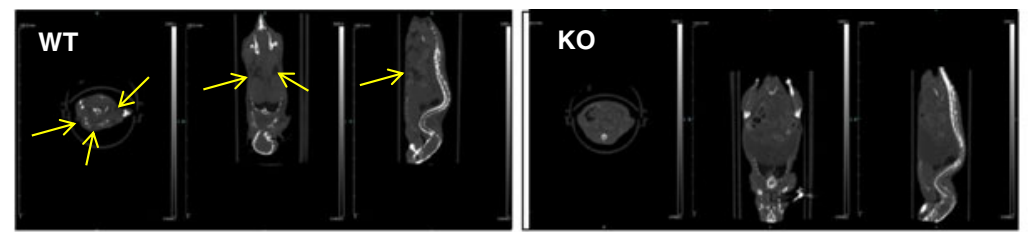

b
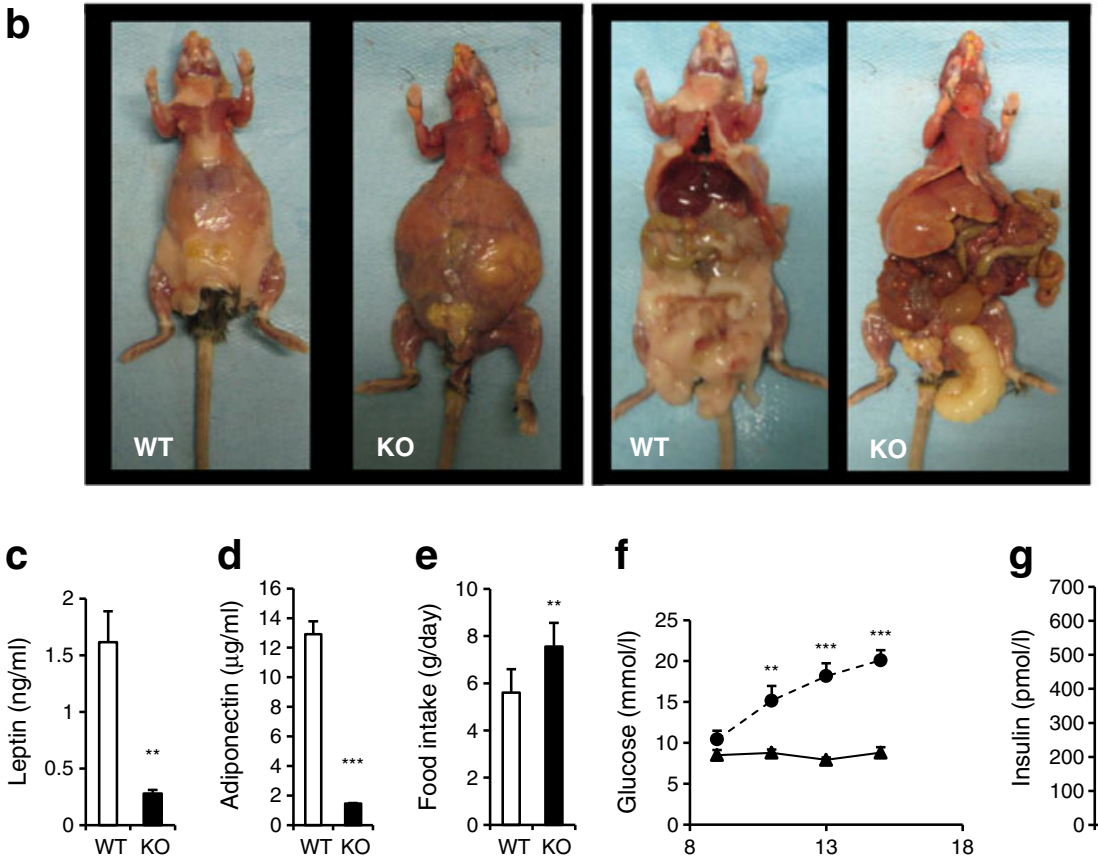

f
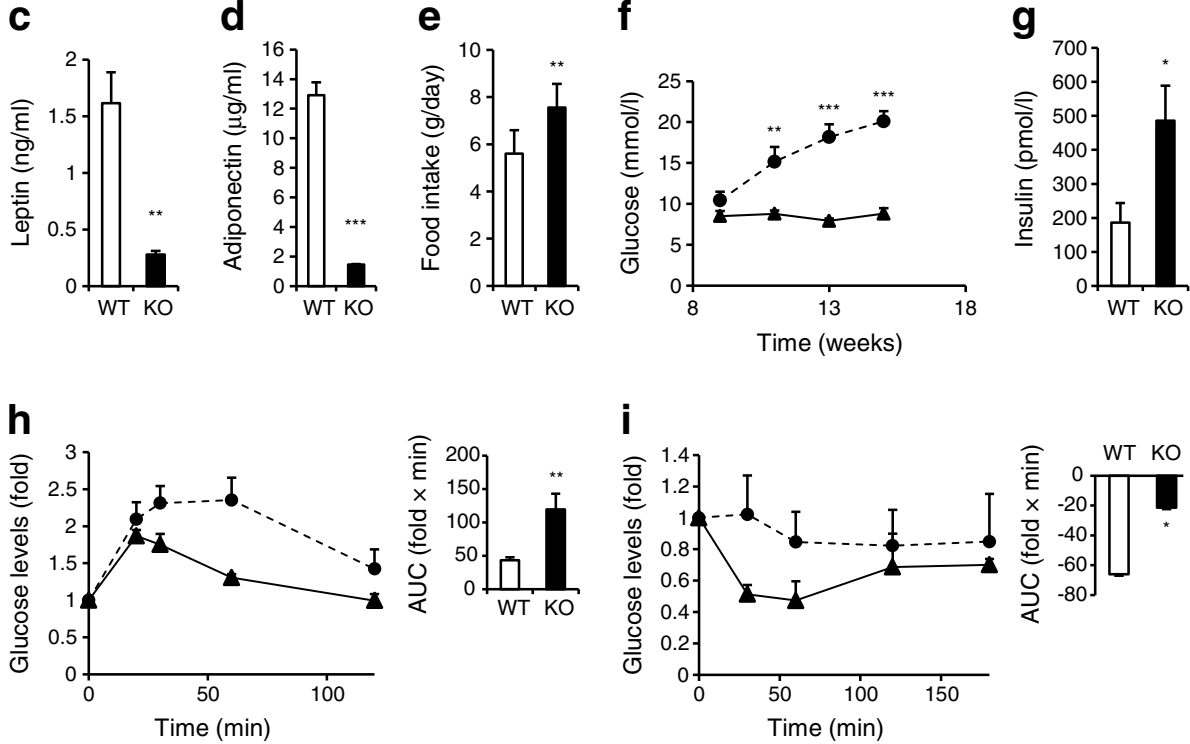

i
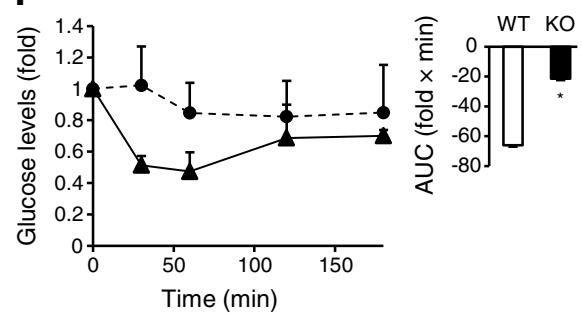
tomography (CT) system (Inveon; Siemens, Erlangen, Germany). Mice were scanned at 9, 13, 17 and 22 weeks of age using the same variables. The X-ray source tube voltage was set at $45 \mathrm{keV}$ with a constant $500 \mu \mathrm{A}$ current for $320 \mathrm{~ms}$. Rotation of $1^{\circ}$ was used to generate images of $110 \mu \mathrm{m}$ pixel resolution. Three-dimensional reconstructions and analysis of adipose tissue variables were performed using COBRA (Siemens) and ITK-Snap software (www.itksnap.org), respectively [18].

Glucose and insulin tolerance tests Food was removed $6 \mathrm{~h}$ before the initiation of the intra-peritoneal glucose tolerance test (IPGTT) or the insulin tolerance test (ITT). At time 0 , a single dose of glucose $(2 \mathrm{~g} / \mathrm{kg})$ or insulin $(0.75 \mathrm{U} / \mathrm{kg}$ Actrapid; Novo Nordisk, Chartres, France) was administered by i.p. injection and blood glucose levels were monitored using a glucometer (Freestyle Papillon; Abbot, Rungis, France) on $2.5 \mu \mathrm{l}$ samples collected from the tail.

In vivo lipid metabolism To produce ${ }^{3} \mathrm{H}$-labelled VLDLcholesterol, $185 \mathrm{MBq}$ of $\left[{ }^{3} \mathrm{H}\right]$ palmitate (PerkinElmer, Courtaboeuf, France) was evaporated, resuspended in $4 \mathrm{ml}$ of $0.5 \mathrm{mmol} / 1$ fatty acid-free BSA/DMEM solution and shaken at $37^{\circ} \mathrm{C}$ for $2 \mathrm{~h}$. Male C57B16/J mice were anaesthetised with xylazine/ketamine/PBS mixture (1:1:8, vol./vol./vol.) and then given a retro-orbital vein injection of $9.25 \mathrm{MBq}$ radiolabelled palmitate solution. After injection, blood was collected and $\left[{ }^{3} \mathrm{H}\right]$ VLDL-cholesterol was isolated by ultracentrifugation using a 1.006 density saline solution and dialysed in PBS for $24 \mathrm{~h}$. Triacylglycerol-rich lipoproteins (TRLs) were collected from C57B16/J mice $1 \mathrm{~h}$ after olive oil gavage. The TRL solution $(1 \mathrm{ml}, 1 \mathrm{mg} / \mathrm{ml}$ protein concentration) was placed in a pre-coated Iodogen tube (PerkinElmer) and 14.8 MBq of ${ }^{125} \mathrm{I}$ was added. After $6 \mathrm{~h}$ of fasting, $\mathrm{Bscl}^{-/-}$or wild-type mice anaesthetised with xylazine/ketamine/PBS (1:1:8, vol./vol./vol.) solution received $100,000 \mathrm{cpm}$ of $\left[{ }^{3} \mathrm{H}\right] \mathrm{VLDL}$-cholesterol or $1,000,000 \mathrm{cpm}$ of ${ }^{125}$ I-labelled TRL. Blood sampling was performed at the indicated times.

Energy expenditure measurement $\mathrm{O}_{2}$ consumption, $\mathrm{CO}_{2}$ production, activity and food and water intake were measured using the physiocage system (Panlab, Barcelona, Spain). Mice were acclimatised for $48 \mathrm{~h}$, and measurements were performed during the following $48 \mathrm{~h}$.

RNA analysis Total RNA from tissues was purified using Trizol (Life technology, les Ulis, France) according to the manufacturer's instructions. Total RNA from cell samples was purified with the NucleoSpin RNA II (Macherey Nagel, Hoerdt, France). Total RNA (500 ng) was reversetranscribed and real-time quantitative PCR was performed using the TaqMan 7900 Sequence Detection System
(Applied Biosystems, Warrington, UK). Primers were designed using the Primer Express 3.1 software (Life Technology, les Ulis, France, sequence available on request). Results are represented as arbitrary units indicating relative expressions by calculation based on the comparative $\mathrm{C}_{\mathrm{t}}$ (also called $\Delta \mathrm{C}_{\mathrm{t}}$ ) methods after normalisation to cyclophilin or 36B4 as the reference genes (indicated in the figure legend where applicable).

Isolation and culture of MEFs $\mathrm{Bscl}^{+/-}$pregnant female mice were killed at 12.5-14.5 days post-coitum, embryos were collected and MEFs were isolated. Adipocyte differentiation, oil red $\mathrm{O}$ staining and lipolysis assay were performed as previously described [19, 20]. For Bodipy staining, cells were grown on glass coverslips, fixed in $4 \%$ paraformaldehyde and stained with Bodipy 493/503 (Life technology) for $30 \mathrm{~min}$.

Lipid extraction and measurement Cell and tissue samples were homogenised in lysis buffer mixed with four volumes of chloroform/methanol (2/1, vol./vol.). After being shaken for $1 \mathrm{~h}$, samples were centrifuged $20 \mathrm{~min}$ at $500 \mathrm{~g}$. The organic (lower) phase was placed in a new tube, evaporated under $\mathrm{N}_{2}$ and resuspended in the appropriate volume of isopropanol. A $10 \mu$ l volume was evaporated in a 96-well plate for determination of TAG content.

Statistical analysis All data were reported as means \pm SEM. Data sets were analysed for statistical significance using the non-parametric Mann-Whitney $U$ test or, when mentioned in the figure legend, two-way ANOVA analysis; ${ }^{*} p<0.05$, $* * p<0.01$ and $* * * p<0.001$.

\section{Results}

$\mathrm{Bscl}^{-/}$mice are severely lipodystrophic and diabetic We generated $\mathrm{Bscl}^{-1-}$ mice by gene targeting based on the mutation identified in BSCL2 in patients with BSCL (i.e. a large deletion, including exons 4-6) [2, 21] (ESM Fig. 1a). Because homozygous $\mathrm{Bscl}^{-/-}$male mice were sterile, the colony was maintained by crossing heterozygous $\mathrm{Bscl}^{+/-}$ mice. Genotypes at embryonic day 12 followed a mendelian pattern $\left(24 \% \mathrm{Bscl}^{+/+}, 53 \% \mathrm{Bscl}^{+/-}\right.$, and $23 \% \mathrm{Bscl}^{-/-} ; n=$ 117 embryos) but the ratio of $B s c l 2^{-/-}$mice surviving after weaning was only $18 \%(n=126,3$-week-old mice $)$, suggesting an increased perinatal death.

Consistent with the human BSCL phenotype, seipin deficiency led to a severe generalised lipodystrophy in mice. $\mathrm{X}$-ray micro-CT analysis showed that 2-month-old male $\mathrm{Bscl}^{-/-}$mice displayed a near-total lipoatrophy (Fig. 1a). However, total body weight did not differ between genotypes during ageing (ESM Fig. 1b). Dissection revealed that 
peri-gonadal fat pads were completely absent, with a genuine organomegaly of the liver, intestine, kidneys and epididymal canal in $\mathrm{Bscl}^{-/-}$mice (Fig. 1b). Liver weight was twofold increased in $\mathrm{Bscl}^{-/-}$compared with wild-type mice (Table 1). A reduced, but still measurable, residual mass of mesenteric and inguinal WAT was present in $\mathrm{Bscl}^{-1-}$ mice. Interscapular brown adipose tissue (BAT) was reduced, but still present, in 2-month-old $\mathrm{Bscl}^{-/-}$mice. In accordance with lipodystrophy, circulating levels of both leptin and adiponectin were significantly reduced (Fig. 1c, d) and daily food intake was increased by $37 \%$ (Fig. 1e).

$\mathrm{Bscl}^{-1-}$ mice displayed random-fed hyperglycaemia starting at 9 weeks of age and worsening with ageing (Fig. 1f), while fasting plasma glucose remained unchanged (data not shown). Fasting insulinaemia was significantly increased in $\mathrm{Bscl}^{-/-}$mice (Fig. 1g). IPGTT and ITT demonstrated that $\mathrm{Bscl}^{-/-}$mice exhibited both glucose intolerance and severe insulin resistance (Fig. 1h, i).

Seipin deficiency accelerates liver clearance of TRL Although hypertriglyceridaemia is a common feature of patients with BSCL [1], 2-month-old $\mathrm{Bscl}^{-1-}$ mice displayed a $40 \%$ decrease in plasma TAG in both the fasted and random-fed state (Fig. 2a). Plasma NEFA levels were also decreased by $40 \%$ in $\mathrm{Bscl}^{-/-}$mice in the fasted state, but not in the random-fed state (Fig. 2b). In contrast, seipin deficiency did not alter fasted total cholesterol levels (Fig. 2c). The cholesterol-lipoprotein profile revealed a weak decrease in LDL-cholesterol and a slight increase in large and apolipoprotein E-rich HDLcholesterol in $\mathrm{Bscl2}^{-/-}$mice (Fig. 2d).

We measured VLDL-TAG secretion rate using the lipoprotein lipase inhibitor tyloxapol, which blocks TAG clearance from the bloodstream [17]. As shown in Fig. 2e, the hepatic VLDL-TAG secretion rate was similar in both genotypes. In addition, intestinal chylomicron production, measured after intravenous injection of tyloxapol followed by an oral gavage of olive oil, did not vary between genotypes (Fig. 2f). Then, we studied the clearance of both
VLDL and chylomicrons by labelling TRL on fatty acids and protein moieties using $\left[{ }^{3} \mathrm{H}\right]$ palmitate (lipid moiety) (Fig. 2g) and ${ }^{125} \mathrm{I}$ (protein moiety) (Fig. 2h). Two minutes after injection, the radioactivity in plasma was decreased by $20 \%$ and $60 \%$, respectively in wild-type mice and in $\mathrm{Bscl}^{-/-}$mice, indicating an increased TRL clearance in $\mathrm{Bscl}^{-1-}$ mice. The difference was maintained over $30 \mathrm{~min}$. Consistently, the liver content of ${ }^{3} \mathrm{H}$ and ${ }^{125} \mathrm{I}$ was increased in $\mathrm{Bscl}^{-/-}$mice (Fig. 2i, j).

Thiazolidinediones partially restore the function of Bscl2 ${ }^{-/-}$ adipocytes in vitro To identify pharmacological strategies for improving the metabolic complications associated with lipodystrophy, we studied the effect of TZDs on $\mathrm{Bscl}^{-/}$ adipocyte function. In MEFs isolated from wild-type and $\mathrm{Bscl}^{-1-}$ mice, Oil Red O staining revealed that both rosiglitazone and pioglitazone increased the number of lipid-loaded cells (Fig. 3a). Rosiglitazone increased TAG content by twofold in $\mathrm{Bscl}^{-/-}$MEFs (Fig. 3b). Next, we measured the expression levels of early and late markers of adipocyte differentiation during adipogenesis [22]. Cebp mRNA levels were reduced in $\mathrm{Bscl}^{-/-}$MEFs, suggesting that seipin has an impact on early adipogenesis (Fig. 3c). The induction of Pparg (Fig. 3d) and Cebpa (ESM Fig. 2) mRNA was lower in $\mathrm{Bscl}^{-/-}$mice 2 days after the beginning of adipocyte differentiation. In mature adipocytes (day 9), Pparg, Ap2 (also known as Fabp4, encoding adipocyte fatty acid binding protein) and Adipoq (encoding adiponectin) expression levels were reduced by more than twofold in $\mathrm{Bscl}^{-/-}$cells (Fig. 3d-f). While rosiglitazone was able to fully restore Pparg and Adipoq expression levels at day 4 in $\mathrm{Bscl}^{-/-}$cells (Fig. 3d, f), it only partially restored $A p 2$ mRNA levels throughout the adipogenic programme (Fig. 3e).

As LDs play a key role in the control of lipid storage, we analysed their morphology in both genotypes using Bodipy 493/503 coloration. While wild-type cells displayed multiple round and well-delimited small LDs, $\mathrm{Bscl}^{-/-}$MEFs displayed large and often unique LDs (Fig. $3 \mathrm{~g}$ ). Rosiglitazone restored a multiple/well-defined pattern of

Table 1 Organ weight after 9 weeks of pioglitazone treatment

\begin{tabular}{lllll}
\hline Organ/tissue & \multicolumn{2}{l}{ Wild-type mice } & & \multicolumn{2}{c}{ Bscl2 ${ }^{-/-}$mice } \\
\cline { 2 - 4 } & Control & Pioglitazone & Control & $26 \pm 2^{\dagger}$ \\
\hline Whole body (g) & $29 \pm 3$ & $28 \pm 4$ & $32 \pm 4$ & $1,622 \pm 231^{\dagger}$ \\
Liver (mg) & $1,081 \pm 215$ & $1,110 \pm 160$ & $2,905 \pm 110^{* *}$ & $65 \pm 22^{\dagger}$ \\
BAT (mg) & $96 \pm 40$ & $244 \pm 97$ & $33 \pm 12^{* *}$ & $103 \pm 28^{\dagger}$ \\
Mesenteric WAT (mg) & $193 \pm 46$ & $196 \pm 62$ & $29 \pm 15^{* *}$ & $53 \pm 25^{\dagger \dagger}$ \\
Inguinal WAT (mg) & $170 \pm 27$ & $272 \pm 66$ & $17 \pm 7^{* *}$ & \\
\hline
\end{tabular}

Data are means \pm SEM, $n=6$ per group

${ }^{*} p<0.05,{ }^{* *} p<0.01 \mathrm{KO}$ control compared with WT control; ${ }^{\dagger} p<0.05,{ }^{\dagger \dagger} p<0.01$, pioglitazone-treated wild-type compared with control wild-type mice 


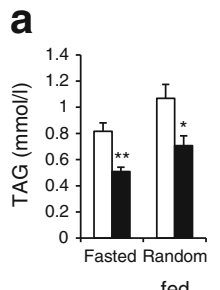

fed

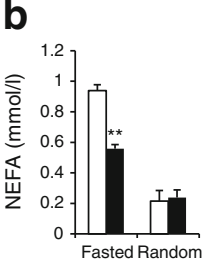

fed
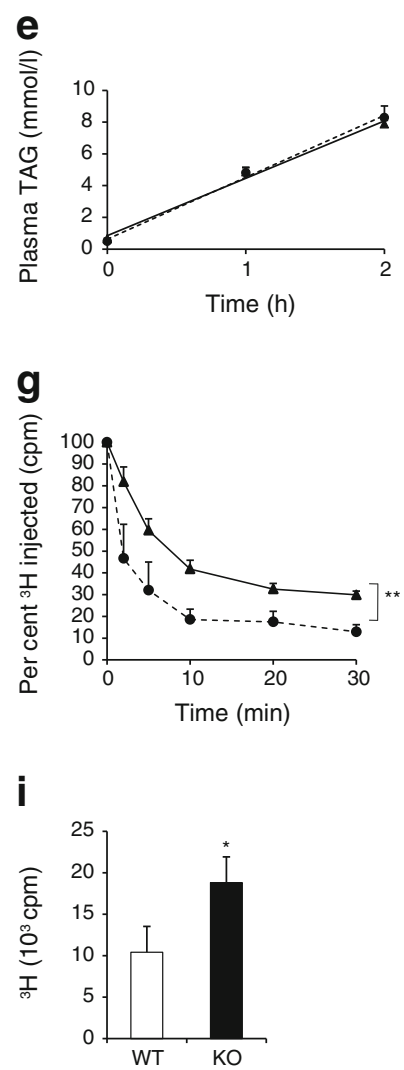

Fig. 2 Dysfunction of lipid metabolism in $\mathrm{Bscl}^{-/-}$mice. Levels of TAG (a), NEFA (b) and total cholesterol (c) measured using a colorimetric method (see Methods section for details) in 2-month-old male wild-type (white bars, WT) and $B s c l 2^{-/-}$(black bars, KO) mice. (d) Cholesterol-lipoprotein profile of a pool of wild-type (solid line) and $\mathrm{Bscl}^{-/-}$(dashed line) mice established using FPLC. Plasma TAG reflecting (e) VLDL secretion evaluated after an intravenous injection of tyloxapol in fasted mice according to the equations $y=3.45 x+0.55$ and $\mathrm{y}=3.20 \mathrm{x}+0.75$ for wild-type and $\mathrm{Bscl}^{-/-}$mice, respectively and (f) TRL (chylomicron+VLDL) secretion measured after injection of tyloxapol followed by an olive oil gavage in 3-month-old wild-type

LDs in $\mathrm{Bscl}^{-/-}$MEFs, even though the large/unique LD phenotype was still present in a few cells.

A fourfold increase in basal glycerol release was observed in $\mathrm{Bscl2}^{-/-} \mathrm{MEFs}$, indicating an increase in basal lipolysis (Fig. 3h). In contrast, isoprenaline (isoproterenol)-stimulated lipolysis was similar in both genotypes. Rosiglitazone tended to reduce this increase in basal lipolysis rate in $\mathrm{Bscl}^{-/-}$cells without reaching significance.
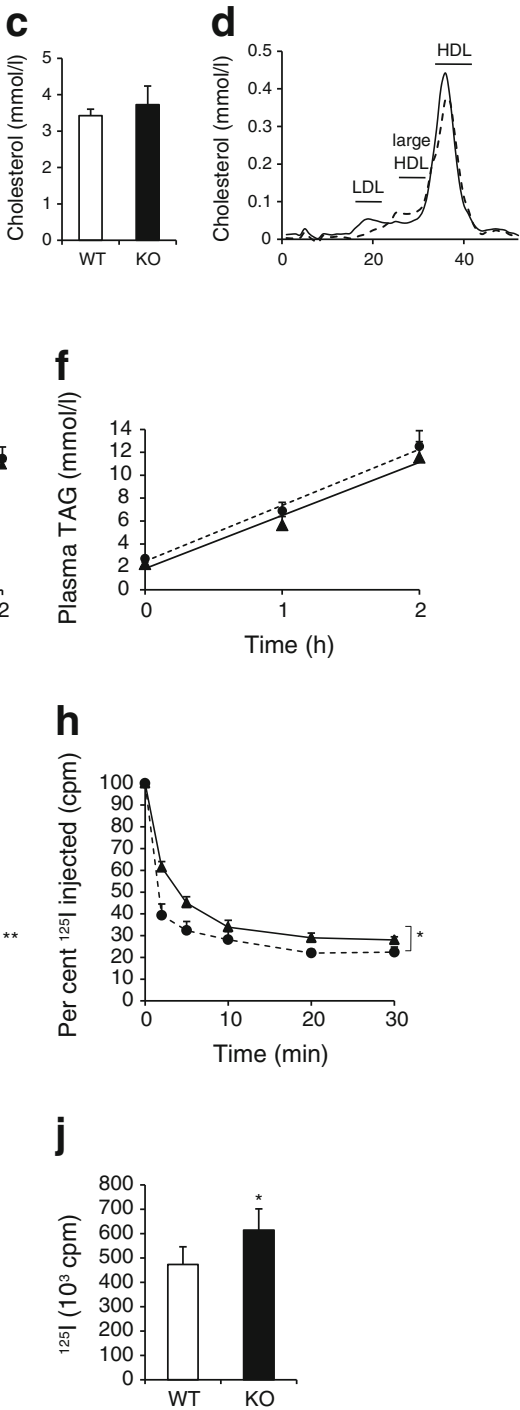

(triangle, solid line) and $\mathrm{Bscl}^{-/-}$(circle, dashed line) mice according to the respective equations $y=4.11 \mathrm{x}+1.63$ and $\mathrm{y}=4.33 \mathrm{x}+2.19$. (g) $\left[{ }^{3} \mathrm{H}\right]$ palmitate- and (h) $\left[{ }^{125} \mathrm{I}\right] \mathrm{TRL}-\mathrm{labelled}$ VLDL clearances measured for $30 \mathrm{~min}$ after intravenous injection in fasted 3-month-old male wildtype (triangle, solid line) and $\mathrm{Bscl}^{-/-}$(circle, dashed line) mice. The statistical significance was assessed by two-way ANOVA. (i,j) Total amount of radioactivity in the liver of wild-type (WT) and $\mathrm{Bscl}^{-/}$ (KO) mice measured at the end of the experiment $(n=8$ mice per group). The bars represent the SEM; ${ }^{*} p<0.05,{ }^{*} p<0.01$ compared with wild-type mice

Pioglitazone improves insulin sensitivity in vivo in $\mathrm{Bscl}^{-/-}$ mice In a next step, we assessed whether a TZD could improve metabolic variables in vivo in $\mathrm{Bscl}^{-/-}$mice. Onemonth-old $\mathrm{Bscl}^{-1-}$ male mice were fed a pioglitazoneenriched $(300 \mathrm{mg} / \mathrm{kg})$ diet for 9 weeks. Pioglitazone normalised both random-fed plasma glucose and fasting insulin levels and significantly improved insulin sensitivity assessed by ITT (Fig. 4a-d). Pioglitazone also tended to improve glucose tolerance without reaching statistical 
Fig. 3 Effect of rosiglitazone treatment on adipocyte differentiation and lipolysis rate in seipin-deficient cells. MEFs from wild-type and $\mathrm{Bscl}^{-/-}$embryos were differentiated into adipocytes (see Methods section for details). Nine days after induction of adipocyte differentiation, the total amount of TAG was evaluated using Oil Red $\mathrm{O}$ staining (a) and a colorimetric method (b). In (a), WT, wildtype; $\mathrm{KO}, \mathrm{Bscl}^{--1}$; in (b), Cont, control; Rosi, rosiglitazone; white bar, wild-type; black bar, $\mathrm{Bscl}^{-/}$. (c-f) During the differentiation time course, the expression of adipogenic genes was measured by real-time quantitative PCR at different times after induction of differentiation of MEFs. Results are represented as arbitrary units indicating relative expressions after normalisation to cyclophilin as the reference gene. Control conditions in wild-type (white bars) and $\mathrm{Bscl}^{-/-}$(dark-grey bars) cells, and following treatment with $1 \mu \mathrm{mol} / 1$ rosiglitazone in wild-type (lightgrey bars) and $\mathrm{Bscl2}^{-/-}$(black bars) cells. ${ }^{*} p<0.05,{ }^{*} p<0.01$, $* * * p<0.001, B s c l^{-/-}$compared with wild-type MEFs in each condition (with or without rosiglitazone). (g) LD morphology was evaluated by Bodipy 493/503 staining. (h) Lipolysis was quantified from the glycerol released in serum-free but BSA-supplemented media during $4 \mathrm{~h}$ in the absence or presence of isoprenaline (white bar, wild-type cells; black bar, $\mathrm{Bscl}^{-/-}$cells). Experiments were performed in triplicate. The bars represent the SEM; ${ }^{*} p<0.05$, $*^{*} p<0.01, \mathrm{Bscl}^{-/-}$cells compared with wild-type cells in each condition (with or without rosiglitazone)
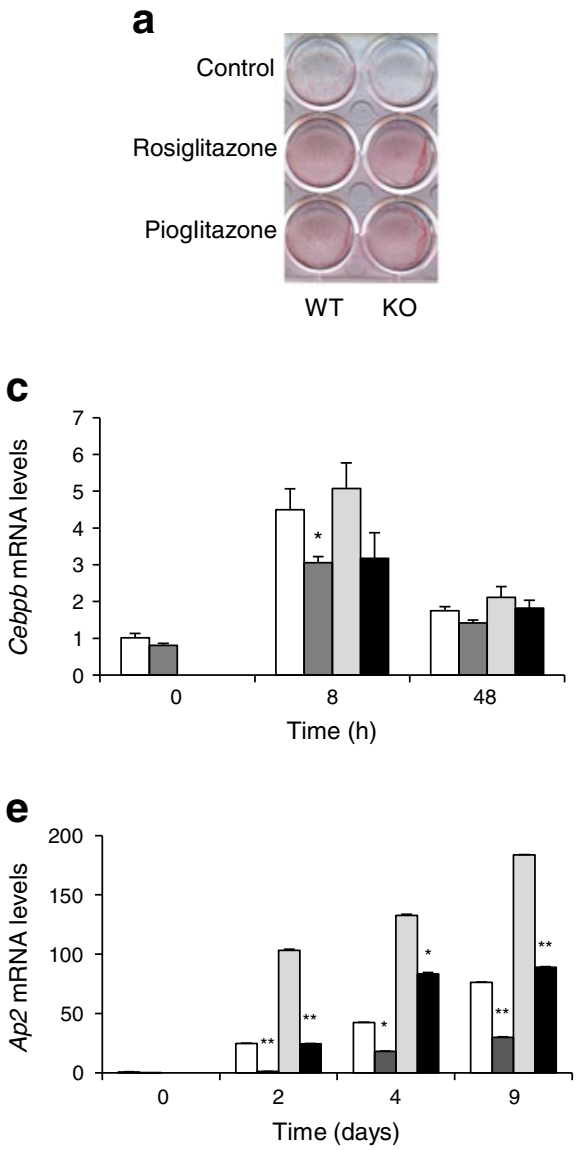

g

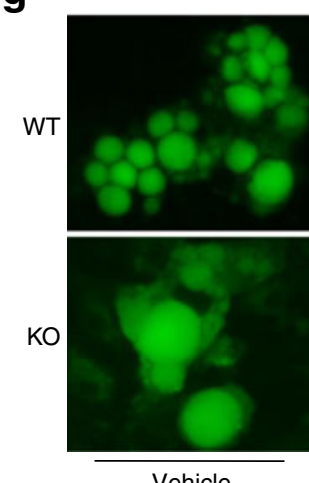

Vehicle

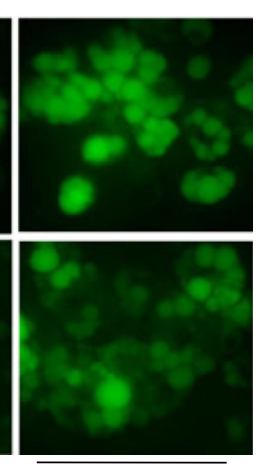

Rosiglitazone d

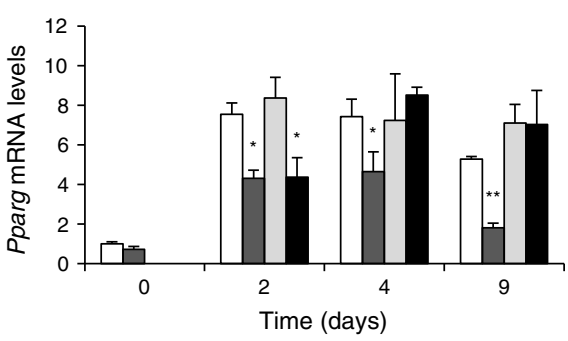

f

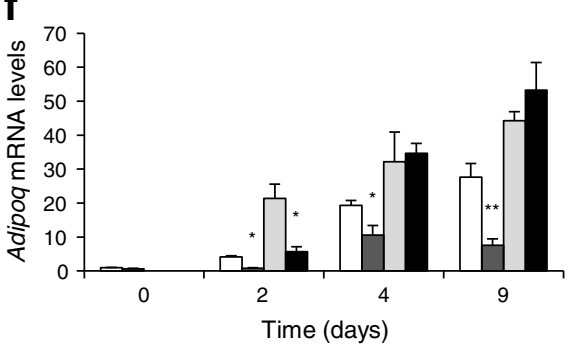

h

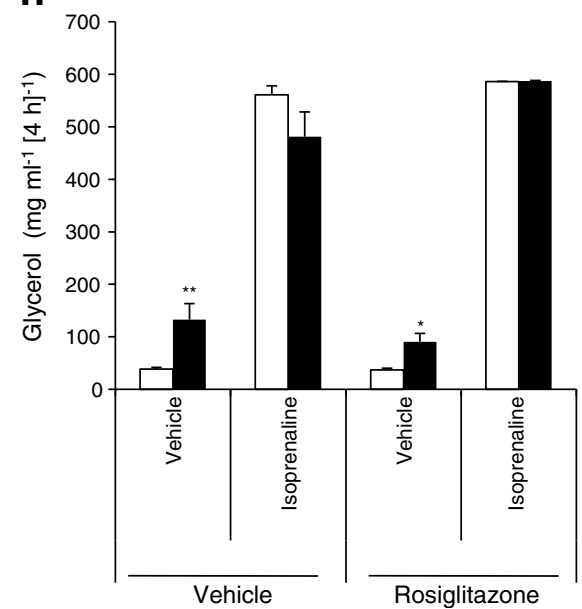

significance (ESM Fig. 3a). Pioglitazone increased plasma levels of adiponectin and leptin (Fig. 4e, f) and induced a threefold increase in the weight of residual mesenteric and inguinal fat pads (Table 1). While Cebpb expression was not impaired, Pparg, Lep (encoding leptin), Adipoq, Plin1 (encoding perilipin A) and Lipe (encoding hormone-sensitive lipase [HSL]) mRNA levels were reduced in the inguinal fat pad of $\mathrm{Bscl}^{-/-}$compared with wild-type mice (Fig. 4g). b

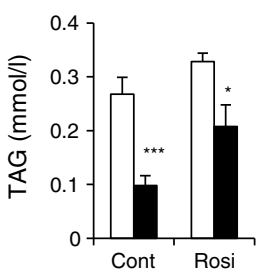


Fig. 4 Effect of TZD treatment on metabolic variables associated with BSCL. Onemonth-old $\mathrm{Bscl}^{-/-}$(KO) and wild-type (WT) male mice were fed for 9 weeks with either a normal chow diet (white bars) or a chow diet supplemented with pioglitazone (black bars, $300 \mathrm{mg} / \mathrm{kg}$ of diet). (a) Random-fed glucose and (b) insulin levels. (c) ITT (white triangle, control wild-type mice; black triangle, pioglitazone-treated wild-type mice; white circle, control $\mathrm{Bscl}^{-/-}$mice; black circle, pioglitazone-treated $\mathrm{Bscl}^{-/-}$ mice). (d) AUC performed after 6 weeks of treatment. After mice were killed at 9 weeks, adiponectin (e) and leptin (f) levels were evaluated in wildtype and $\mathrm{Bscl}^{-/-}$mice untreated or treated with pioglitazone $(n=9,8,9$ and 6, respectively). (g) Inguinal fat pad gene expression profile in wild-type and $\mathrm{BsCl}^{-\gamma-}$ mice untreated or treated with pioglitazone ( $n=6,5,4$ and 6, respectively). Results are presented as mRNA levels of the indicated target gene normalised to $36 \mathrm{~B} 4 \mathrm{mRNA}$ levels. $* p<0.05, * * p<0.01$ $B s c l 2^{-/}$compared with wildtype mice; ${ }^{\star} p<0.05,{ }^{*} p<0.01$, untreated compared with pioglitazone-treated mice
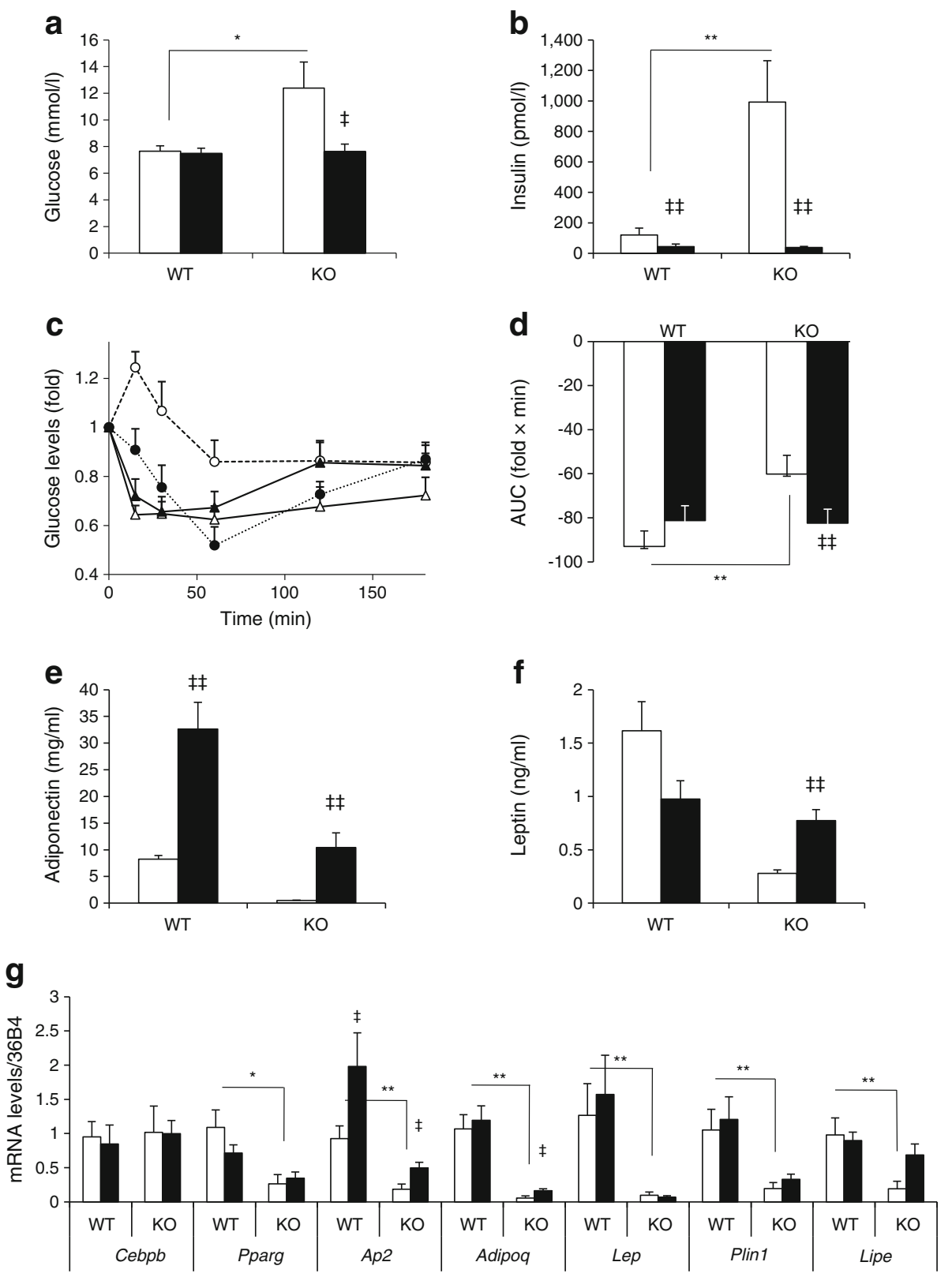

Pioglitazone increases energy expenditure in $\mathrm{Bscl}^{-/-}$ mice Mice were individually placed into metabolism cages to measure the $\mathrm{O}_{2}$ consumption, $\mathrm{CO}_{2}$ production and energy expenditure (Fig. 5a-c). Under basal/untreated conditions, seipin deficiency was associated with a decrease in energy expenditure without any change in physical activity (Fig. 5d). Interestingly, pioglitazone was able to fully restore the metabolic profile of $\mathrm{Bscl}^{-1-}$ mice. These data show that pioglitazone increases the metabolic rate in $\mathrm{Bscl}^{-/-}$mice.

Pioglitazone reduces liver steatosis and restores normal TRL clearance in Bscl2 $2^{-/}$mice As pioglitazone is known to improve liver steatosis [23], we then studied its effect on hepatic lipid metabolism. Both liver weight (Table 1) and
TAG content (Fig. 6a) were strongly reduced in $\mathrm{Bscl}^{-/-}$ mice upon dietary pioglitazone treatment. This was associated with a total body weight loss (Table 1). Circulating FGF-21 levels were increased in untreated $\mathrm{Bscl}^{-/-}$mice compared with wild-type mice (Fig. 6b). In accordance with the reduction in liver steatosis, pioglitazone treatment restored normal FGF-21 levels in $\mathrm{Bscl}^{-1-}$ mice.

To understand the mechanism involved in the reduction of liver steatosis, we reperformed TRL clearance experiments after 9 weeks of pioglitazone treatment. As previously described [24], pioglitazone treatment accelerated TRL clearance in wild-type mice. In contrast, in $\mathrm{Bscl}^{-/-}$mice pioglitazone treatment reduced TRL clearance to a normal rate (Fig. 6c), and consequently lowered the hepatic lipid uptake (Fig. 6d). Normalisation of triglyceridaemia in TZD- 

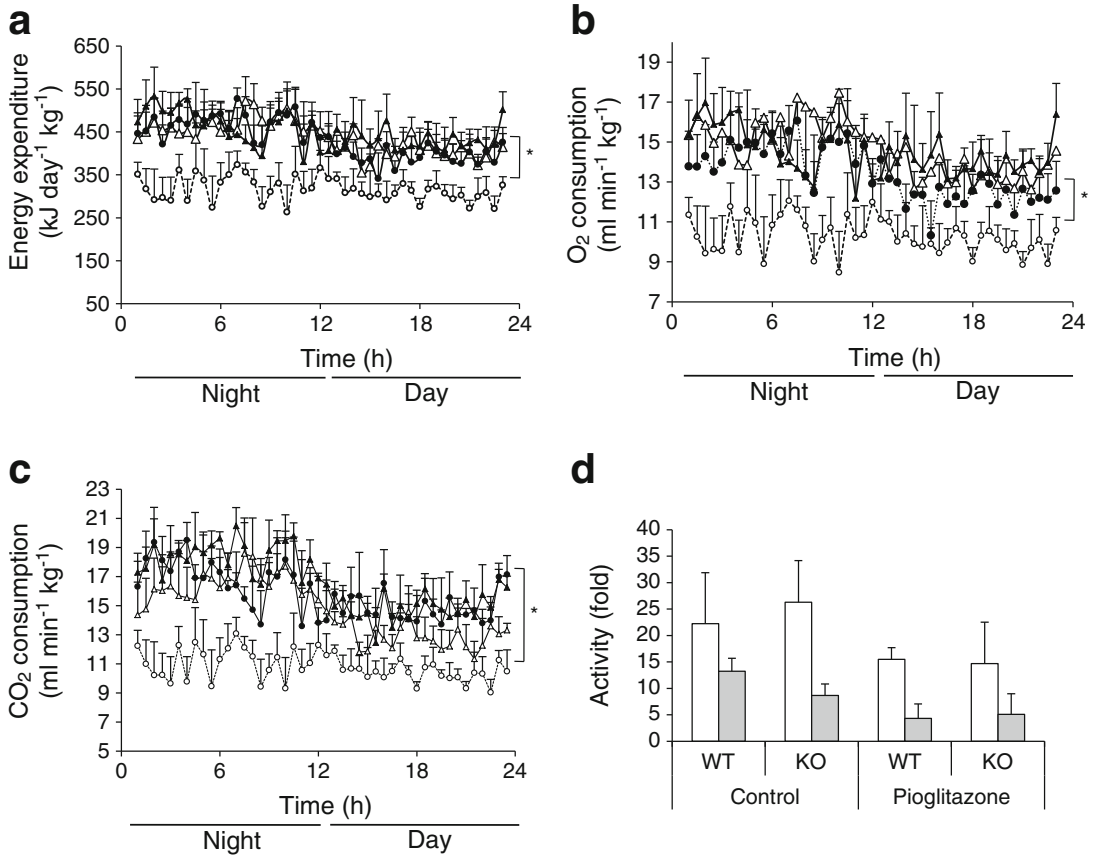

d

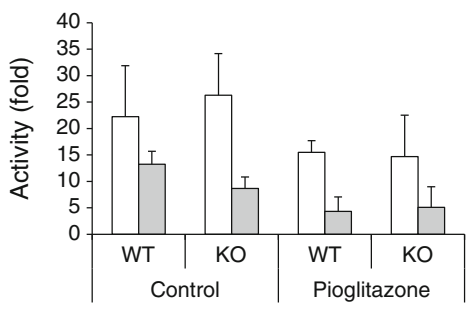

Fig. 5 Effect of TZD treatment on metabolic rate. After 9 weeks of treatment with pioglitazone $(300 \mathrm{mg} / \mathrm{kg}$ of diet), mice were individually placed in the panlab metabolic rate measurement system $(n=4-6)$. (a) Energy expenditure, (b) $\mathrm{O}_{2}$ consumption and (c) $\mathrm{CO}_{2}$ production measured every $30 \mathrm{~min}$. White triangle, control wild-type mice; black triangle, pioglitazone-treated wild-type mice; white circle, control

treated $\mathrm{Bscl}^{-/-}$mice was consistent with this finding (ESM Fig. 4).

Pparg mRNA expression, which was induced in the steatotic liver of untreated $\mathrm{Bscl}^{-/-}$mice, was also drastically reduced following pioglitazone treatment (ESM Fig. 5a). Similarly, mRNA levels of the lipogenic transcription factor Srebplc (also known as Srebfl, encoding sterol response element binding protein-1c [SREBP-1c]) and its target genes, Fas (also known as Fasn) and Scdl (encoding stearoyl coenzyme A desaturase 1), which were upregulated in $\mathrm{Bscl}^{-1-}$ mice, were significantly reduced upon pioglitazone treatment (ESM Fig. 5b-d). In contrast, pioglitazone treatment did not alter the expression of genes involved in NEFA oxidation, such as Cpt1a (encoding carnitine palmitoyltransferase 1) (ESM Fig. 5f). Finally, mRNA levels of both $C d 36$ and $L d l r$ (encoding the LDL receptor [LDLr]) were reduced in pioglitazone-treated $\mathrm{Bscl}^{-/-}$mice (ESM Fig. $5 \mathrm{~g}$, h). The protein level of LDL receptor (LDLr) was also reduced in pioglitazone-treated $\mathrm{Bscl}^{-/-}$mice, whereas the scavenger receptor (CD36) protein remained unchanged (Fig. 6e).

\section{Discussion}

Based on the characterisation of a new $\mathrm{Bscl}^{-/-}$mouse model, the present work gives further insights into the metabolic

$B s c l 2^{-/-}$mice; black circle, pioglitazone-treated $B s c l 2^{-/-}$mice. ${ }^{*} p<$ $0.05 \mathrm{Bscl}^{-/}$compared with wild-type mice, assessed by 2-way ANOVA. (d) Cumulative locomotor activity during night (white bars) and day (grey bars), in wild-type (WT) and $\mathrm{Bscl}^{-/-}$(KO) mice untreated (Control) and treated with pioglitazone. Results are represented as the mean counts per $12 \mathrm{~h} \pm$ SEM

function of seipin, which plays a major part in the pathogenesis of BSCL in humans [2]. First, we confirm that seipin deficiency leads to severe lipodystrophy, profound insulin resistance and ultimately diabetes, perfectly reflecting observations made in patients with BSCL. Second, we demonstrate that $\mathrm{Bscl}^{-/-}$ mice exhibit an unexpected hypotriglyceridaemia due to an increase in hepatic TRL and NEFA uptake, leading to severe liver steatosis. Last, we show that in vivo treatment with a TZD (i.e. pioglitazone) improves insulin sensitivity, metabolic rate and liver steatosis in $\mathrm{Bscl}^{-/}$mice.

It is now accepted that seipin is crucial for full adipogenesis [13,14] but the effect of pharmacological activation of PPAR $\gamma$ by TZDs on adipocyte differentiation in seipin-deficient cells remains controversial $[14,15]$. In our study, TZD normalised the expression levels of PPAR $\gamma$ and its target gene, Adipoq, while it only partially rescued the Ap2 mRNA levels in $B s c l 2^{-/-}$MEFs. Accordingly, in human fibroblasts isolated from a patient with BSCL, pioglitazone induced the expression of adipogenic markers such as $A P 2$ and lipoprotein lipase [25]. Consistent with a beneficial effect of TZDs on adipocyte function, intracellular TAG concentration was increased and LD morphology pattern was partially normalised in treated $\mathrm{Bscl}^{-/}$ MEFs. An increase in basal, but not $\beta_{3}$-agonist-stimulated lipolysis was observed in $\mathrm{Bscl}^{-/-}$MEFs and this default also likely contributes to the inability of seipin-deficient 
Fig. 6 Effect of TZD treatment on hepatic lipid metabolism. After 9 weeks of feeding with control diet (white bars) or pioglitazone-supplemented diet (300 mg/kg of diet; black bars), hepatic TAG was measured after lipid extraction (a) and circulating FGF-21 was evaluated (b) in wild-type (WT) and $\mathrm{Bscl}^{-/-}(\mathrm{KO})$ mice. (c) $\left[{ }^{3} \mathrm{H}\right]$ palmitate-labelled VLDL clearance was evaluated for 10 min following intravenous injection in fasted male mice. White triangle, control wildtype mice; black triangle, pioglitazone-treated wild-type mice; white circle, control $\mathrm{Bscl2}^{-/-}$mice; black circle, pioglitazone-treated $\mathrm{Bscl}^{-}{ }^{-}$ mice. (d) Total radioactivity was counted in the liver in control (white bars) and pioglitazonetreated (black bars) mice ( $n=4$ 6 mice per group). (e) Western blot of hepatic lysate from wildtype and $\mathrm{BsCl}^{-1-}$ mice untreated or treated with pioglitazone (PIO). Fold values represent the LDLr and CD36 protein levels evaluated by densitometric analysis (Image $\mathbf{J}$ software) and normalised to $\beta$-actin levels. * $p<0.05, \mathrm{Bscl}^{-/-}$ compared with wild-type mice; ${ }^{\star} p<0.05,{ }^{\star \star} p<0.01$, untreated compared with pioglitazonetreated mice a

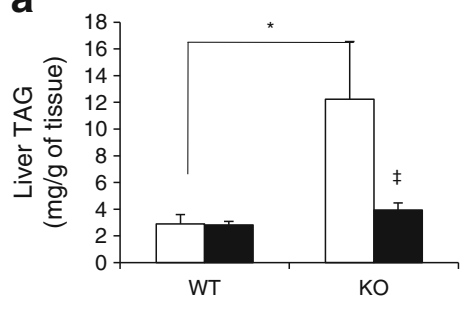

C
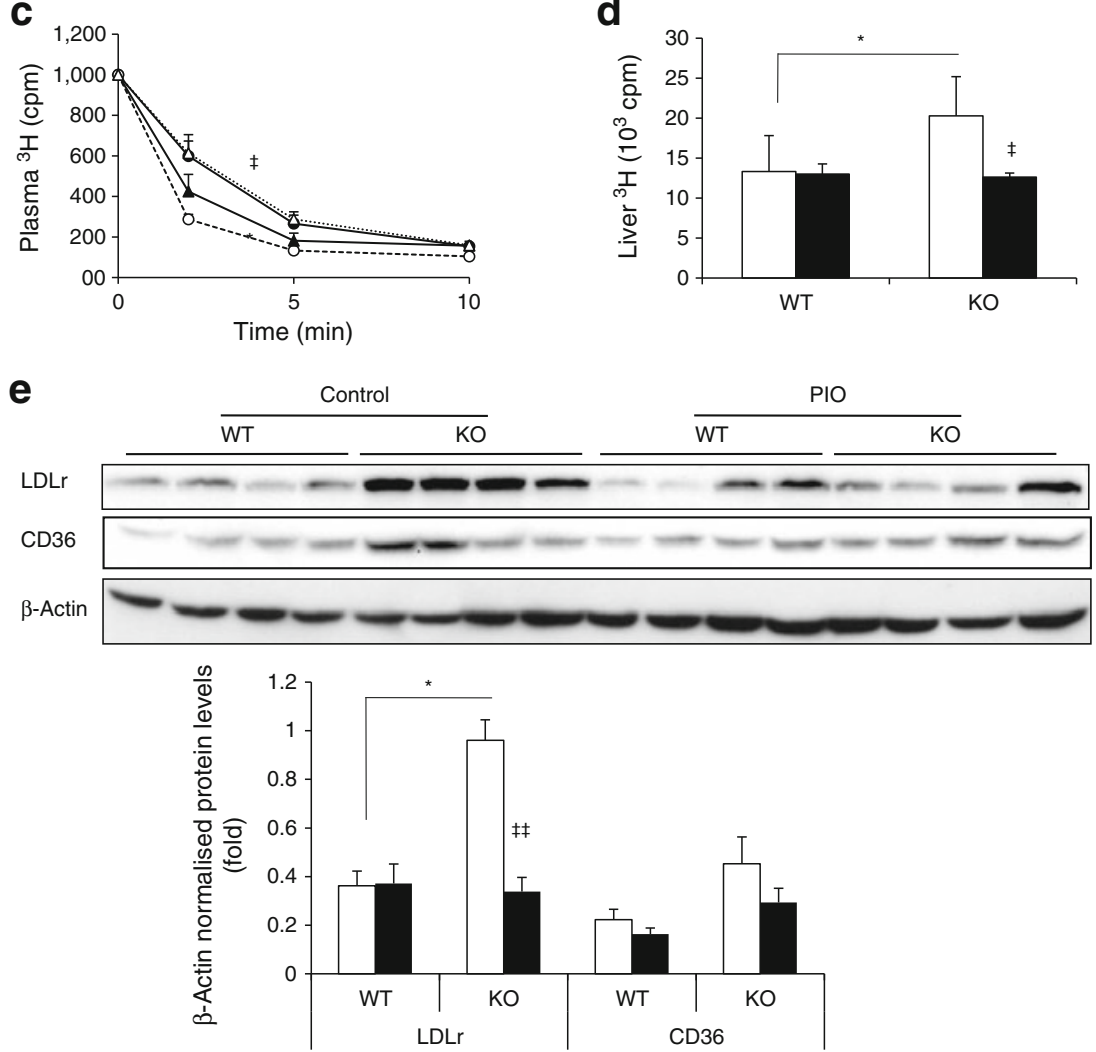

b

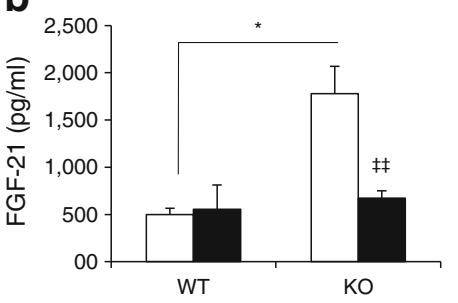

d

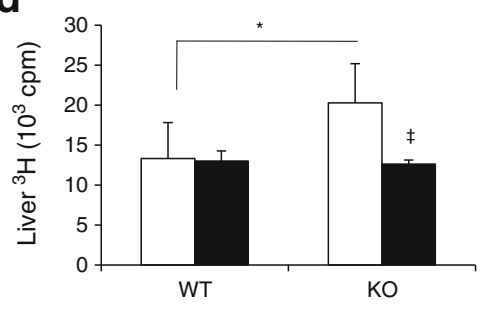
. adipocytes to store lipids. Recently, Chen et al reported that this increased lipolysis was dependent on cAMP protein kinase A activation and could be corrected by a lipase inhibitor [15]. We confirm here that TZDs failed to correct this default in lipolysis [15]. Taken together, these results suggest that seipin deficiency has two major consequences for adipocyte function: (1) a default in the late adipogenic programme, which is largely improved by TZDs and (2) an intrinsic default in lipolysis rate, which is resistant to TZDs.

One of the key findings is that pioglitazone can efficiently improve insulin sensitivity, random-fed glucose levels and liver steatosis in $\mathrm{Bscl}^{-/}$mice. This effect is surprising since TZDs failed to improve glucose homeostasis in AZIP/F-1 mice, which totally lack WAT [26]. This suggests that pioglitazone likely improves insulin sensitivity in Bscl2 $2^{-1-}$ mice by promoting adipose tissue expansion (thereby reducing lipotoxicity) and adiponectin secretion from residual fat depots. To further explore seipin function in 
brought about by TZD treatment was only partial. PPAR $\gamma$ activation was able to restore some mature adipocyte features in $\mathrm{Bscl}^{-/-}$mice but not all, suggesting that some seipin actions remain independent of PPAR $\gamma$.

Although hypertriglyceridaemia is a common feature in patients with lipodystrophy [1], $\mathrm{Bscl}^{-/-}$mice displayed an unexpected decrease in plasma TAG levels in both the fed and fasted states, in agreement with the findings of other reports $[15,16]$. Based on a decreased expression of hepatic microsomal TAG transfer protein, Cui et al suggested that liver steatosis and hypotriglyceridaemia in $\mathrm{Bscl}^{-/-}$mice ensued from impaired VLDL secretion [16]. In our mouse model, however, neither hepatic VLDL-TAG output nor intestinal secretion of chylomicron were impaired. Using in vivo lipoprotein kinetics, we demonstrated that the TRL catabolic rate was strongly increased in $\mathrm{Bscl}^{-1-}$ mice. This observation is consistent with the increase in both NEFA and lipoprotein hepatic uptake, which might contribute to liver steatosis. Pioglitazone treatment was able to correct the increased TRL uptake by the liver observed in $\mathrm{Bscl}^{-/-}$ mice. In contrast, in wild-type mice, pioglitazone treatment increased TRL clearance without affecting the hepatic lipid uptake as this effect is usually mediated by VLDL receptor upregulation in WAT [24]. This suggests an additional mechanism to explain the effect of pioglitazone on TRL clearance in the context of seipin deficiency. One hypothesis is that the upregulation of hepatic LDLr expression in $B s c l 2^{-/-}$mice may contribute to the altered lipid phenotype. The LDLr is a key player in hepatic uptake of VLDL [27] and its expression is increased in the liver of insulin-resistant mice [28]. This induction has been attributed to SREBP-1c overexpression in response to hyperinsulinaemia, without any change in SREBP-2 expression [28, 29]. In liver from $\mathrm{Bscl}^{-/}$mice, LDLr expression was indeed increased and pioglitazone treatment was able to decrease LDLr at similar levels to wild-type mice. The decrease in insulinaemia observed in pioglitazone-treated $\mathrm{Bscl} 2^{-/-}$mice likely contributes to the decrease in SREBP-1c and LDLr levels and, subsequently, to normalisation of liver TRL clearance. The decreased expression of lipogenic genes that follows SREBP-1c expression might also contribute to the improvement of liver steatosis. Alternatively, pioglitazone treatment might also reduce liver steatosis by promoting lipid use, since it increases metabolic rate and energy expenditure in $\mathrm{Bscl}^{-/-}$mice. This effect could result from the increase in adiponectinaemia, which was shown to induce NEFA oxidation in liver and to reduce hepatic TG content [23]. Accordingly, the total plasma ketone body concentration was increased in pioglitazone-treated $\mathrm{Bscl2}^{-/-}$mice (data not shown). This finding apparently contrasts with previous studies of TZD treatment in animal models of lipodystrophy. Chao et al have shown that in A-ZIP/F-1 mice, TZD treatment increased rather than decreased liver steatosis [26]. Using liver-specific PPAR $\gamma$ deficient mice, Gavrilova et al demonstrated that this effect was strictly dependent on the activation of hepatic PPAR $\gamma$ [30]. Although we cannot rule out a cellautonomous effect of seipin in liver, our results suggest that the beneficial reduction of liver steatosis observed in $\mathrm{Bscl}^{-/-}$mice treated with pioglitazone is sustained by the activation of adipose PPAR $\gamma$ in the residual fat depots.

Our results open new perspectives for the treatment of patients with BSCL and are in accordance with the findings of a study in which rosiglitazone improved insulin sensitivity and decreased $\mathrm{HbA}_{1 \mathrm{c}}$ in a patient with BSCL2. Rosiglitazone also increased plasma leptin levels while moderately decreasing liver lipogenic enzymes [25]. However, dual X-ray absorptiometry analysis failed to reveal a significant increase in fat mass upon rosiglitazone treatment, likely due to a lack of sensitivity of the method. This raises the question of the presence of remaining fat pads in BSCL patients, although the presence of WAT in BSCL2 patients has been detected by different techniques (dual energy X-ray densitometry or magnetic resonance imaging) [31,32]. Actually, recombinant leptin injection is the gold-standard therapy in adults $[33,34]$ and children [35] with BSCL. However, some BSCL patients progressively develop leptin resistance due to the production of leptin antibodies [36]. Additional clinical studies are warranted to determine whether TZDs represent a valid alternative option for the treatment of BSCL.

In conclusion, our study confirms that $\mathrm{Bscl}^{-/-}$mice exhibit a severe lipodystrophy associated with diabetes, liver steatosis and unexpected hypotriglyceridaemia. This specific lipid phenotype, due to an increased uptake of TRL and NEFA by the liver, offers a new model of liver steatosis. Finally, we demonstrate that the metabolic complications associated with BSCL can be partially rescued by pioglitazone in vivo, reinforcing the observation by Victoria et al [25] that TZD might be a therapeutic option for BSCL patients.

Acknowledgements We thank L. Arnaud (Inserm UMR_S1087, L'Institut du Thorax, Nantes, France) for technical assistance and M. Pla (Département d'Expérimentation Animale, Saint-Louis Hospital, Paris, France) for transferring mice. We thank P. Casanova, T. Ledent, D. Muller and I. Renaud (Inserm animal facility, SaintAntoine Hospital, Paris, France) as well as T. Boyer, A. Lefèbvre, S. Lemarchand-Minde and V. Maurier (Animal facility, L'Institut du Thorax, Nantes, France) for animal care. We are grateful to E. Boutet, H. El Mourabit, M. Prot (Inserm UMR_S938, Saint-Antoine Faculty of Medicine, Paris, France) and A. S. Bierinx and A. Sébille (Atelier de régénération neuromusculaire, Faculté de Médecine Saint-Antoine, Université Pierre et Marie Curie-Paris 6, Paris, France) for mouse phenotyping and to P. Cervera and S. Dumont (Service d'Anatomie Pathologique, Hôpital Saint-Antoine, Paris, France) for histology studies. We thank B. Fellah, M. Fuselier and J. Rousseau (Platform of Medical Imaging - ONIRIS, National College of Veterinary Medicine, Nantes, France) for microscanner analyses. 
Funding This work was supported by grants from the Institut National de la Santé et de la Recherche Médicale (Inserm), the French Ministère de la Recherche et de la Technologie (MRT) and French associations (Aide aux Jeunes Diabétiques [AJD], Fondation de France, Fondation GenaVie and Association de Langue Française pour l'Etude du Diabète et des Maladies Métaboliques [ALFEDIAM]/Société Francophone du Diabète [SFD]). L. Dollet received a grant from the MRT and M. Nemani received grants from the Région Ile-de-France and AJD.

Duality of interest The authors declare that there is no duality of interest associated with this manuscript.

Contribution statement XP, MT, FM, ML, JC, BC, PC and JM contributed to the conception and design of the experimental procedure. XP, LD, MT, MN, BP, HTI, DZ and JM contributed to the acquisition and the analysis of data. All authors participated in the analysis and interpretation of data. XP, BC and JM drafted the article and LD, MT, MN, BP, CLM, CM, HTI, DZ, FM, BF, JC, ML and PC revised it critically for important intellectual content. All authors approved the final version of the manuscript.

\section{References}

1. Capeau J, Magré J, Caron-Debarle M et al (2010) Human lipodystrophies: genetic and acquired diseases of adipose tissue. Endocr Dev 19:1-20

2. Magré J, Delépine M, Khallouf E et al (2001) Identification of the gene altered in Berardinelli-Seip congenital lipodystrophy on chromosome 11q13. Nat Genet 28:365-370

3. Agarwal AK, Arioglu E, de Almeida S et al (2002) AGPAT2 is mutated in congenital generalized lipodystrophy linked to chromosome 9q34. Nat Genet 31:21-23

4. Kim C, Delépine M, Boutet E et al (2008) Association of a homozygous nonsense caveolin-1 mutation with BerardinelliSeip congenital lipodystrophy. J Clin Endocrinol Metab 93:1129-1134

5. Hayashi YK, Matsuda C, Ogawa M et al (2009) Human PTRF mutations cause secondary deficiency of caveolins resulting in muscular dystrophy with generalized lipodystrophy. J Clin Invest 119:2623-2633

6. Cohen AW, Hnasko R, Schubert W, Lisanti MP (2004) Role of caveolae and caveolins in health and disease. Physiol Rev 84:1341-1379

7. Szymanski KM, Binns D, Bartz R et al (2007) The lipodystrophy protein seipin is found at endoplasmic reticulum lipid droplet junctions and is important for droplet morphology. Proc Natl Acad Sci USA 104:20890-20895

8. Cartwright BR, Goodman JM (2012) Seipin: from human disease to molecular mechanism. J Lipid Res 53:1042-1055

9. Fei W, Du X, Yang H (2011) Seipin, adipogenesis and lipid droplets. Trends Endocrinol Metab 22:204-210

10. Fei W, Li H, Shui G et al (2011) Molecular characterization of seipin and its mutants: implications for seipin in triacylglycerol synthesis. J Lipid Res 52:2136-2147

11. Fei W, Shui G, Gaeta B et al (2008) Fld1p, a functional homologue of human seipin, regulates the size of lipid droplets in yeast. J Cell Biol 180:473-482

12. Wolinski H, Kolb D, Hermann S, Koning RI, Kohlwein SD (2011) A role for seipin in lipid droplet dynamics and inheritance in yeast. J Cell Sci 124:3894-3904
13. Payne VA, Grimsey N, Tuthill A et al (2008) The human lipodystrophy gene BSCL2/seipin may be essential for normal adipocyte differentiation. Diabetes 57:2055-2060

14. Chen W, Yechoor VK, Chang BH, Li MV, March KL, Chan L (2009) The human lipodystrophy gene product BSCL2/seipin plays a key role in adipocyte differentiation. Endocrinology 150:4552-4561

15. Chen W, Chang B, Saha P et al (2012) Berardinelli-Seip congenital lipodystrophy $2 /$ seipin is a cell-autonomous regulator of lipolysis essential for adipocyte differentiation. Mol Cell Biol 32:10991111

16. Cui X, Wang Y, Tang Y et al (2011) Seipin ablation in mice results in severe generalized lipodystrophy. Hum Mol Genet 20:30223030

17. Lambert G, Jarnoux AL, Pineau T et al (2006) Fasting induces hyperlipidemia in mice overexpressing proprotein convertase subtilisin kexin type 9: lack of modulation of very-low-density lipoprotein hepatic output by the low-density lipoprotein receptor. Endocrinology 147:4985-4995

18. Yushkevich PA, Piven J, Hazlett HC et al (2006) User-guided 3D active contour segmentation of anatomical structures: significantly improved efficiency and reliability. NeuroImage 31:1116-1128

19. Cariou B, van Harmelen K, Duran-Sandoval D et al (2006) The farnesoid $\mathrm{X}$ receptor modulates adiposity and peripheral insulin sensitivity in mice. J Biol Chem 281:11039-11049

20. Abdelkarim M, Caron S, Duhem C et al (2010) The farnesoid X receptor regulates adipocyte differentiation and function by promoting peroxisome proliferator-activated receptor-gamma and interfering with the Wnt/beta-catenin pathways. J Biol Chem 285:36759-36767

21. Boutet E, El Mourabit H, Prot M et al (2009) Seipin deficiency alters fatty acid Delta9 desaturation and lipid droplet formation in Berardinelli-Seip congenital lipodystrophy. Biochimie 91:796-803

22. Rosen ED, Walkey CJ, Puigserver P, Spiegelman BM (2000) Transcriptional regulation of adipogenesis. Genes Dev 14:12931307

23. Cariou B, Charbonnel B, Staels B (2012) Thiazolidinediones and PPARgamma agonists: time for a reassessment. Trends Endocrinol Metab 23:205-215

24. Tao H, Aakula S, Abumrad NN, Hajri T (2010) Peroxisome proliferator-activated receptor-gamma regulates the expression and function of very-low-density lipoprotein receptor. Am J Physiol Endocrinol Metab 298:E68-E79

25. Victoria B, Cabezas-Agricola JM, Gonzalez-Mendez B et al (2010) Reduced adipogenic gene expression in fibroblasts from a patient with type 2 congenital generalized lipodystrophy. Diabet Med 27:1178-1187

26. Chao L, Marcus-Samuels B, Mason MM et al (2000) Adipose tissue is required for the antidiabetic, but not for the hypolipidemic, effect of thiazolidinediones. J Clin Invest 106:1221-1228

27. Ishibashi S, Brown MS, Goldstein JL, Gerard RD, Hammer RE, Herz J (1993) Hypercholesterolemia in low density lipoprotein receptor knockout mice and its reversal by adenovirus-mediated gene delivery. J Clin Invest 92:883-893

28. Shimomura I, Bashmakov Y, Horton JD (1999) Increased levels of nuclear SREBP-1c associated with fatty livers in two mouse models of diabetes mellitus. J Biol Chem 274:30028-30032

29. Shimomura I, Matsuda M, Hammer RE, Bashmakov Y, Brown MS, Goldstein JL (2000) Decreased IRS-2 and increased SREBP1c lead to mixed insulin resistance and sensitivity in livers of lipodystrophic and ob/ob mice. Mol Cell 6:77-86

30. Gavrilova O, Haluzik M, Matsusue K et al (2003) Liver peroxisome proliferator-activated receptor gamma contributes to hepatic steatosis, triglyceride clearance, and regulation of body fat mass. J Biol Chem 278:34268-34276 
31. Hegele RA, Joy TR, Al-Attar SA, Rutt BK (2007) Thematic review series: adipocyte biology. Lipodystrophies: windows on adipose biology and metabolism. J Lipid Res 48:14331444

32. Aotani D, Ebihara K, Sawamoto N et al (2012) Functional magnetic resonance imaging analysis of food-related brain activity in patients with lipodystrophy undergoing leptin replacement therapy. J Clin Endocrinol Metab 97:3663-3671

33. Javor ED, Cochran EK, Musso C, Young JR, Depaoli AM, Gorden P (2005) Long-term efficacy of leptin replacement in patients with generalized lipodystrophy. Diabetes 54:19942002
34. Ebihara K, Kusakabe T, Hirata M et al (2007) Efficacy and safety of leptin-replacement therapy and possible mechanisms of leptin actions in patients with generalized lipodystrophy. J Clin Endocrinol Metab 92:532-541

35. Beltrand J, Beregszaszi M, Chevenne D et al (2007) Metabolic correction induced by leptin replacement treatment in young children with Berardinelli-Seip congenital lipoatrophy. Pediatrics 120:e291-e296

36. Beltrand J, Lahlou N, Le Charpentier T et al (2010) Resistance to leptin-replacement therapy in Berardinelli-Seip congenital lipodystrophy: an immunological origin. Eur J Endocrinol 162:1083-1091 